\title{
Black Sabbath y el cronotopo del carnaval.
}

\section{Black Sabbath and the carnival cronotope.}

Esta obra está bajo una Licencia Creative Commons Atribución 4.0 Internacional. DOI: $10.32870 /$ sincronia.axxiii.n75.9a19

\author{
Bianca Natascha Pérez González \\ Universidad de Guadalajara \\ nataschaperez18@gmail.com \\ (MÉXICO)
}

Recibido: 06/08/2018

Revisado: $22 / 11 / 2018$

Aprobado: 03/12/2018

\section{Resumen}

El carnaval, según Mijail Bajtin, es el fin último de las actividades sociales, pues es en el cronotopo de la festividad carnavalesca donde el ser humano logra alcanzar el idílico triunfo de una liberación temporal.

El sentimiento de atracción hacia la transgresión de paradigmas, el escándalo, la irreverencia, la paganización de los mitos religiosos, así como la desacralización de las figuras de poder, hacen del Heavy Metal un arquetipo moderno del carnaval medieval, espacio - tiempo que la banda inglesa de Heavy Metal, Black Sabbath, transformará en el cronotopo de su canción titulada "Heaven and Hell", cuyo fundamento es dirigir hacia una catarsis transitoria a través del espectáculo musical.

El cronotopo, es una categoría literaria acuñada por Bajtin para denominar la “intervinculación esencial de las relaciones temporales y espaciales" (Beristáin, 2010, p.117), en la cual el tiempo se vuelve histórico en tanto que se da en un espacio determinado, mismo que queda marcado por las señales del desarrollo de la historia humana, es decir, por una sociedad en particular. En síntesis, el cronotopo se define como el espacio - tiempo que propicia las condiciones particulares para que un evento histórico (social) ocurra. 
Palabras clave: Mijail Bajtin. Catarsis. Utopía. Espectáculo. Ritual. Heavy Metal.

\begin{abstract}
The carnival, according to Mikhail Bakhtin, is the ultimate goal of social activities, since it is in the chronotope of the carnival festivity that the human being manages to achieve the idyllic triumph of a temporary liberation.

The feeling of attraction towards the transgression of paradigms, the scandal, the irreverence, the paganization of religious myths, as well as the desacralization of power figures, make Heavy Metal a modern archetype of medieval carnival, space - time that the band English Heavy Metal, Black Sabbath, will become the chronotope of his song entitled "Heaven and Hell", whose foundation is to direct towards a transitory catharsis through the musical show.

The cronotope, is a literary category coined by Bajtin to call the "essential interlinking of temporal and spatial relationships" (Beristáin, 2010, p.117), in which time becomes historical as long as it occurs in a given space, which is marked by the signs of the development of human history, that is, by a particular society. In short, the chronotope is defined as the space - time that propitiates the particular conditions for a historical (social) event to occur.
\end{abstract}

Keywords: Mikhail Bakhtin. Catharsis. Utopia. Spectacle. Ritual. Heavy Metal.

Disfraces, máscaras, excesos, gozo, risas, humor, colores, bufones. El teatro, el espectáculo, lo absurdo, lo obsceno, lo báquico: carnaval. Oscuridad, excesos, gozo. Gritos de ira, de éxtasis, de euforia; lo irracional, lo pagano, lo negro, lo estridente, lo oculto, lo liberador, lo underground: Heavy Metal.

Juntos o por separado, todos estos elementos constituyen el ambiente para la reformulación de las concepciones ideológicas que rigen la sociedad moral, sagrada y lineal de los últimos años de 
la década de 1960 en Inglaterra; todos ellos constituyen el escenario para presenciar la carnavalización de la vida cotidiana.

A través de la transgresión del espacio, el tiempo y el protocolo social, Black Sabbath ha sido una de las bandas pioneras del movimiento del metal pesado que ha favorecido en sus producciones líricas la creación de un nuevo espacio-tiempo utópico donde se abolen los cánones oficiales para dar paso al goce vitalista y a la festividad altamente permisiva dentro de un mundo idílico que transcurre simultáneamente con el mundo real: el cronotopo del carnaval.

Tres son los rasgos fundamentales del carnaval: Las formas y rituales del espectáculo, las obras cómicas verbales y el vocabulario familiar y grosero (Bajtin, 1980, p.3). Todos ellos constituyen a su vez el discurso carnavalesco de las canciones de Sabbath, aunque en esta ocasión se analizará únicamente la canción que da nombre a la novena producción discográfica de la banda: "Heaven and Hell".

Para comenzar, es imprescindible analizar las formas rituales del espectáculo carnavalesco del Heavy Metal presentes en la canción de Black Sabbath. Primeramente, las acciones descritas implican las formas y rituales del carnaval en tanto que menciona tres elementos clave del espectáculo festivo: el cantante, como parte del espectáculo musical; el carrusel, como parte del espectáculo circense y el bailarín, como parte del espectáculo musical y teatral.

Asimismo, están presentes los reyes y las reinas pero no de la risa, como propone Bajtin, sino de la prestidigitación y la ilusión, quienes poseen la habilidad de engañar la vista del espectador para robar sus sueños: "El mundo está lleno de reyes y reinas, que ciegan tus ojos y roban tus sueños"1.

Se trata, finalmente, de un engaño y un robo que no son condenados, sino aplaudidos como parte del espectáculo de entretenimiento que es el carnaval, donde los planos reales se trastocan para invertirse y crear "una dualidad del mundo" (Bajtin, 1980, p.4): “el final es sólo el comienzo/

\footnotetext{
${ }^{1}$ The world is full of kings and Queens / who blind your eyes and steal your dreams.
} 
cuanto más te acerques al sentido/ más pronto sabrás que estás soñando" 2 (Black Sabbath, Heaven and Hell 1980). Una visión distinta de la existencia y las relaciones humanas, donde el final es el comienzo, el cielo y el infierno conviven en un mismo plano espacio- temporal, así como el mundo real -no festivo- se contrapone al mundo onírico, donde todo es realizable pero, a su vez, ficticio: "bien, si parece real, es una ilusión" ${ }^{3}$.

El mundo utópico se presenta en el sueño, enmarañando la frontera espacio- temporal de la vigilia y el sueño, la realidad y la ilusión, la abstinencia y la permisividad carnavalesca, para situar al personaje en un punto donde el cielo y el infierno se pueden fusionar, conviviendo en ese espacio real, aunque indefinido y abstracto, en el que reside el yo. No se apela a la vuelta de la Edad de Oro, antes bien se propone la creación de un espacio ideal posterior, que viene a alterar la temporalidad lineal con la evocación del futuro hacia el presente.

Así como el carnaval es la fiesta de los excesos, la liberación y el hartazgo de los sentidos previos al periodo de abstinencia, en "Heaven and Hell", Black Sabbath propone la satisfacción de estas mismas necesidades en el otro mundo, el mundo del sueño, antes de volver a la realidad atestada de prohibiciones contra lo mundano.

De esta manera, lo lúdico toma el espacio de lo real cotidiano y la vida se transforma en una imagen del juego del carnaval, representado dentro del texto por la metáfora de la vida como carrusel: "Dicen que la vida es un carrusel/ que gira rápido, tienes que saber montarlo bien." ${ }^{4}$, donde lo abstracto se vuelve concreto, el tiempo se altera y acelera a la vez que se vuelve cíclico, ya que el carrusel encarna en sí el paso del tiempo de manera circular, el mito del eterno retorno, así como el ascenso y descenso que se experimenta sobre los caballitos durante el trayecto en círculo de la existencia simboliza lo bueno y lo malo que cohabitan en la realidad cotidiana, el arriba y el abajo: el Cielo y el Infierno.

\footnotetext{
2 "the ending is just a beginner / the close you get to the meaning / the sooner you'll know that you're dreaming"

3 "well, if it seems to be real, it's illusion"

4 "They say that life is a carousel / spinning fast, you've got to ride it well"
} 
En este sentido, a lo largo de toda la canción vemos que en cuestión temporal, el avance lineal ya no se pondera, así como en cuestión espacial el arriba y el ascenso ya no representan el ideal al cual aspiran a llegar los seres, antes bien, lo vertical y lo superior, bajan para mezclarse con lo inferior y lo horizontal, donde se encuentra el verdadero placer.

Del mismo modo que con el tiempo, los límites del espacio se abolen: ya no existen los espacios concretos y delimitados, sino que hay una superposición de espacios míticos como el cielo y el infierno con los espacios terrenales, lo cual genera una coexistencia de contrarios en armonía: Es el cielo y el infierno, te dirán que el negro en realidad es blanco y que la luna es sólo el sol de la noche ${ }^{5}$.

Las obras cómico-verbales son otro rasgo esencial en el carnaval. La recurrencia a los géneros bajos o populares de la literatura es necesaria, pues permite realizar parodias y mofas sobre las figuras de poder para eliminar las distancias jerárquicas y no hay mejor ejemplo de "baja literatura" que las letras de canciones, género que además de ser considerado por muchos como ajeno a lo literario se posiciona como un género popular, de fácil acceso a cualquier estrato social en tanto que su difusión es posible a través de los medios de comunicación masiva. No se trata de "alta literatura", sino de "literatura del pueblo" que si bien deja un poco de lado el factor del humor, siempre ha de tener la constante del absurdo, principio fundamental del humor, así como lo jocoso: el goce de los sentidos y el conocimiento a través de lo material.

A pesar de las diferencias de época y género, la expresión lírica de la música semeja en gran medida la expresión de las obras teatrales cómicas de la Edad Media, puesto que ambas tienen como función central la expresión de la cosmovisión popular y carnavalesca de la sociedad, utilizando las formas ideológicas, sintácticas y simbólicas propias del momento histórico de la realidad en la que surgen.

\footnotetext{
5 “It's heaven and hell, oh well / and they'll tell you black is really White / the moon is just the sun at night [...]"
} 
En el caso concreto de "Heaven and Hell" -y como tercer rasgo del carnaval- , el vocabulario familiar y grosero se presentan principalmente en forma de blasfemias y expresiones injuriosas cuya intención consiste en derrumbar las figuras míticas de poder para posicionarlas al nivel del pueblo.

Igualmente, son constantes las invocaciones o alusiones al demonio y a lo maligno con tono de exaltación o afinidad a él, donde se atribuye la maldad no al Rey de las Tinieblas, en tanto que hace mención de él como un ente pasivo que "no hace", antes bien es receptor de invocaciones (órdenes) y lo único que hace es cumplirlas: "Hazme un mal, tú eres el portador del mal/ el diablo nunca es el creador" 6 . Por tanto, es el hombre quien ahora domina el reino de lo perverso, haciendo de Satanás sólo un servidor de sus caprichos.

Pese a la ausencia de groserías o palabras altisonantes, la mención reiterativa de lo demoníaco, así como las constantes construcciones sintácticas donde se mezclan planos opuestos aparentemente de manera armónica, propician la desacralización de los íconos religiosos hasta conjuntar el cielo y el infierno en un mismo lugar de convivencia. El cielo se desploma. Ya no se encuentra "arriba", ya no se asciende al cielo, sino que este baja al plano de la ilusión, la confusión y la oscuridad, llegando así a su desmitificación: su caída.

La figura cristiana del sacrificio y la salvación es puesta en entredicho, pues según Sabbath "el amor puede ser visto como la respuesta, pero nadie sangra por el bailarín" 7. La alusión en este verso a Jesús, quien por amor a la humanidad derramó su sangre para salvarla, es evidente. Sin embargo, antes que exaltarla las desmiente, la niega y la utiliza para poner en duda el precepto fundamental de la religión cristiana: el amor como salvación.

Asimismo, la ponderación de la vida material sobre la espiritualidad e invitación al goce rabelesiano, goliardo, vitalista, conllevan a la desvalorización del pecado y el replanteamiento de las normas morales y religiosas para trastocarlas y así llegar a la liberación de los instintos: “El amante de la vida no es un pecador"8.

\footnotetext{
6 "Do me a wrong you're a bringer of evil / the devil is never a maker"

7 "Love can be seen as the answer, but nobody bleeds for the dancer"

8 "The lover of life is not a sinner"
} 
Cabe rescatar también, la desmitificación de los reyes y reinas como mediadores de Dios en la tierra, ya que son descritos como ladrones y timadores.

Así pues, a lo largo de la canción de Black Sabbath, "Heaven and Hell", se constituye un canon de lo grotesco que corresponde a la inversión de planos que se hace posible a través de la carnavalización, misma que solo es propicia dentro de un espacio y un tiempo alternos a los que transcurren en la vida histórica real del autor, por lo cual es posible afirmar que dentro de la cosmovisión del Heavy Metal existe un cronotopo del carnaval necesario para construir el mundo alterno del realismo grotesco que caracteriza la ideología de este movimiento sociocultural.

Se sabe que el metal pesado aboga por una vida ajena a los reglamentos sociales, culturales, religiosos y morales, encaminada a la satisfacción de las necesidades naturales sin reparar en limitaciones: vivir en un constante carnaval donde ni el tiempo, ni el espacio representen un obstáculo para el goce de lo material y lo sensitivo. La incertidumbre y brevedad de la existencia terrenal hace que Black Sabbath como banda pionera del movimiento establezca como filosofía de vida un nuevo sistema de valores que propicie la liberación del ser y permita realizar series de combinaciones de acciones y acontecimientos que "no forman parte de la serie temporal histórica, ni de la vida corriente" (Bajtin, 1989, p.244).

En "Heaven and Hell", las fronteras espacio- temporales desaparecen. "Los elementos del tiempo se revelan en el espacio y el espacio es entendido y medido a través del tiempo" (1989, p.242), es decir que existe una correspondencia marcada entre el tiempo indefinido, abstracto, superpuesto de la obra y el espacio impreciso, no materializado en una zona geográfica real que se fusiona con planos espaciales con que no podría coexistir en un mismo lugar.

Esta combinación no tradicional propia del cronotopo carnavalesco es, a su vez, la que determina las acciones de paganización, ruptura y desmitificación de las figuras jerárquicas sociales a través de la "lógica al revés", cuya estructura genera un segundo plano existencial (un mundo alterno) que apela a la utopía del disfrute sensorial de la vida, a la eliminación de las jerarquías y a la 
festividad, dentro de la cual todo espacio, todo tiempo y todo rango de poder desaparecen para confundir actor y espectador, realidad y ficción, vigilia y sueño en un festín indefinido.

En síntesis, la visión rabelesiana del Heavy Metal en Black Sabbath responden a la presencia de la estructura espacio- temporal del cronotopo del carnaval, dentro del cual resuenan los ecos de una época donde la sociedad inglesa, como consecuencia del nihilismo posterior a la Segunda Guerra Mundial, comienza a cuestionar las estructuras sociales y morales y a buscar nuevas estructuras que sustituyan a los sistemas sociales disfuncionales. Este breve suceso del tiempo biográfico es el que registra el autor, a través de la voz que habla "entre el cielo y el infierno".

\section{ANEXO}

\section{Heaven and Hell}

\section{(Black Sabbath)}

Sing me a song, you're a Singer

Do me a wrong, you're a bringer of evil

The Devil is never a maker

The less that you give, you're a taker

So it's on and on and on

...it's Heaven and Hell, oh well

The lover of life's not a sinner

The ending is just a beginner

The closer you get to the meaning

The sooner you'll know that you're dreaming

So it's on and on and on

Oh it's on and on and on

It goes on and on and on, Heaven and Hell 
I can tell, fool, fool!

Well, if it seems to be real, it's illusion

For every moment of truth, there's confusion in life

Love can be seen as the answer

But nobody bleeds for the dancer

And it's on and on, on and on and on....

They say that life's a carousel

Spinning fast, you've got to ride it well

The world is full of Kings and Queens

Who blind your eyes then steal your dreams

...it's Heaven and Hell, oh well

And they'll tell you black is really White

The moon is just the sun at night

And when you walk in golden halls

You get to keep the gold that falls

It's Heaven and Hell

No no fool, fool!

You got to bleed for the dancer!

Fool, fool, look for the answer!

Fool, fool, fool!

(Heaven and Hell. Heaven and Hell [CD]. Miami: Warner Bros. Records).

\section{Referencias}

Bajtin, M. (1999) Estética de la creación verbal (10ạ Ed.) México: Siglo XXI. 
Bajtin, M. (1980) La cultura popular en la Edad Media y en el Renacimiento. El contexto de Francois Rabelais, México: Alianza Editorial

Bajtin, M. (1989), Las formas del tiempo y del cronotopo en la novela. Teoría y estética de la novela, Madrid: Taurus. pp.237- 409

Beristáin, H. (2010) Diccionario de retórica y poética. México: Porrúa.

Black Sabbath (1980) Heaven and Hell. Heaven and Hell [CD]. Miami: Warner Bros. Records.

Corral, E. (2005) Algunas palabras sobre la carnavalización literaria. Obtenida el 31 de julio de 2018 de http://cdigital.uv.mx/bitstream/123456789/332/1/2005135P45.pdf 